\title{
LA LUCHA CONTRA EL LAVADO DE ACTIVOS: ¿ESTAMOS AVANZANDO O RETROCEDIENDO? ¿REALMENTE «NUESTRAS AUTORIDADES ESTÁN LUCHANDO CONTRA LA CRIMINALIDAD»? ¿QUÉ FALTA?
}

THE FIGHT AGAINST MONEY LAUNDERING: ARE WE MOVING FORWARD OR BACKWARD?
ARE «OUR AUTHORITIES REALLY FIGHTING AGAINST CRIME»? WHAT ARE WE MISSING?

Shirley Muñico Patilla Queni Rebatta Chirre Pool Orihuela Quispe Andrea Cornelio Montero

Universidad Continental

\section{Resumen}

Actualmente, el delito de activos ha tomado protagonismo dentro de la noticia nacional, debido a los múltiples escándalos en los que se han visto involucradas varias figuras políticas del país. Desde un punto de vista crítico y compaginado con nuestra realidad, vemos, sin duda, alguna que la carencia de preparación de una gran cantidad de funcionarios y servidores públicos que se dedican a la lucha contra el crimen organizado lleva consigo un desmérito, siendo que mientras la actividad fiscal va a pasos pequeños la actividad criminal va en un automóvil. ¿¿Será que nuestras instituciones estatales que tienen por función combatir el lavado de activos y otras formas organizadas de cometer delitos están contaminadas?, la situación es alarmante, debido a que no solo se deja al libre arbitrio de los delincuentes la comisión de ilícitos, sino indirectamente se les deja la facultad de determinar el avance o deterioro económico de un país, propiciando así cada vez más la creación e paraísos económicos. ¿Realmente «nuestras autoridades están luchando contra la criminalidad»? ¿Qué falta?

Palabras clave: Lavado de activos; actividad criminal; delito previo; Unidad de Inteligencia Financiera del Perú, eficacia, Ministerio Público, poder punitivo. 


\section{Abstract}

Currently the crime of assets has taken center stage in the national news due to the multiple scandals in which several political figures of the country have been involved, from a critical point of view and combined with our reality we see that without a doubt the lack of preparation of the civil and public servants who are dedicated to the fight against organized crime, carries with it a demerit, while the fiscal activity goes by small steps the criminal activity goes faster. Will it be that our state institutions, whose function is to fight against the laundering of assets and other organized ways of committing crimes, are contaminated?, the situation is alarming because not only the commission of illicit acts is left to the free will of the criminals, but indirectly they are left with the faculty of determining the advance or deterioration of economic in a country, propitiating more and more the creation of economic paradises. Are «our authorities really fighting against crime»? What are we missing?.

Keywords: Money laundering; criminal activity; prior crime; Unidad de Inteligencia Financiera of Peru; effectiveness, Ministerio Público; punitive power.

\section{INTRODUCCIÓN}

Entre los delitos perseguidos por el Estado, podemos identificar un fenómeno delictivo complejo denominado lavado de activo. Este delito visto como un proceso desde el enfoque criminológico, cuya finalidad es insertar o poner en circulación dinero de origen ilícito en el sistema económico legal, despierta gran debate en su naturaleza y en su tratamiento jurídico en la materia penal.

Diferentes organizaciones internacionales se han pronunciado con respecto al tratamiento y a cómo se debería perseguir este delito, por esta razón, y desde un enfoque exclusivamente jurídico, los legisladores dotaron a cada etapa del proceso llamado lavado de activos de autonomía jurídica para su persecución y sanción. Por tanto, se puede advertir que tanto los actos de conversión, como la tenencia y traslado de dinero obtenido a partir de actos que importan la comisión de un delito, son punibles y gozan de relevancia jurídico penal.

Ante el gran desarrollo doctrinal y jurisprudencial, se presentará un análisis histórico de la regulación nacional sobre este delito, la vinculación de los funcionarios o servidores públicos en la comisión de este delito y un análisis crítico del lavado de activos en un contexto contemporáneo y actual. 
Durante el desarrollo de la investigación será transcendente presentar los datos estadísticos sobre el incremento o disminución de la concurrencia en este delito, lo cual coadyuvará responder la incógnita: ¡es eficaz la lucha contra el delito de lavado de activos?

Una cifra alarmante que no permitirá inferir el sentido de la respuesta es que solo 10 de los casos investigados han llegado a una sentencia condenatoria, lo cual nos permite imaginar cuánto dinero con aparente origen legal es insertado en el circuito socioeconómico legal, así como también si los órganos y funcionarios encargados de perseguir penalmente a los sujetos que cometen este delito se desempeñan con eficacia.

El presente artículo de investigación culminará con propuestas para luchar contra delito de lavado de activos y sobre la importancia de la colaboración interinstitucional que es un factor trascendente para el descubrimiento de pruebas que brinden indicios objetivos para lograr acabar o minimizar la afectación de los bienes jurídicos tutelados.

\section{LO QUE NOS PREOCUPA}

Actualmente el delito de activos ha tomado protagonismo dentro de la noticia nacional, debido a los múltiples escándalos en los que se han visto involucradas varias figuras políticas del país. Según un informe emitido por el Ministerio Público, en el transcurso del año 2017, las fiscalías nacionales especializadas en delitos de lavado de activos recibieron alrededor de 509 denuncias por este ilícito, de los cuales 444 casos fueron resueltos, mientras que 65 aún continúan en trámite, por causa del problema de la excesiva carga procesal. Este número parece alentador comparado con la situación de las fiscalías supraprovinciales de Lima que, si bien es cierto tienen un número menor de denuncias registradas (192 casos), solo 55 de ellas han sido resueltas, y lamentablemente 137 se encuentran en trámite, a la espera de una disposición fiscal, ya sea de archivo o formalización de la investigación preparatoria. En porcentaje, esta cifra se puede traducir en un $71,35 \%$, lo que genera una imagen impropia del sistema fiscal que, a pesar de contar con la ayuda de la División de Investigación de Lavado de Activos (Dirila) y la División Especializada en Delitos de Alta Complejidad (Diviac) de la Policía Nacional del Perú, no ha sabido avanzar correcta y oportunamente con las investigaciones (Ministerio Público, 2017, p. 52). 
Desde un punto de vista crítico y compaginado con nuestra realidad, vemos sin duda alguna que la carencia de preparación una buena parte de los funcionarios y servidores públicos que se dedican a la lucha contra la actividad de crimen organizado lleva consigo un desmérito, siendo que, mientras la actividad fiscal va a pasos pequeños, la criminalidad ha crecido de forma exponencial. ¿¿Será que nuestras instituciones estatales que tienen por función combatir contra el lavado de activos y otras formas organizadas de cometer delitos, están contaminadas? Esta situación es alarmante.

\section{CUESTIONES PRELIMINARES}

La Comunidad Europea elaboró en 1991 la llamada Normativa de la Unión Europea, Directiva N. ${ }^{\circ}$ 91/308/CEE, relativa a la prevención de la utilización del sistema financiero para el lavado de activos. Mediante esta iniciativa se propicia que los estados firmantes ejecuten acciones tendientes a la erradicación o disminución de la comisión del delito de lavado de activos, siendo esta una labor trascendental para el avance de un país.

La Organización de Estados Americanos ha creado la Comisión Interamericana para el Control del Abuso de Drogas (Cicad), la cual en 1992 aprueba el Reglamento modelo americano sobre delitos de lavado de dinero.

El desarrollo de la criminalidad organizada ha llegado a puntos preocupantes, debido a que sus alcances han propiciado el mayor auge de la corrupción, subyugando a los Estados, que han ido, paulatinamente, perdiendo su soberanía. En base a esta premisa, denotamos que la forma necesaria para enfrentar esta circunstancia es mediante el acuerdo mancomunado entre países.

Es preocupante que, en estos últimos tiempos, la autonomía de los entes encargados de la persecución del delito de lavado de activos sea cuestionada. Entonces si estos entes, como en la «mayoría de casos», delegan sus facultades a los delincuentes, simplemente la sociedad está perdida.

El profesor Luigi Ferrajoli de la Universidad de Camerino, en un discurso premonitorio, se pregunta ¿qué ha cambiado a partir del 11 de septiembre?, y luego afirma que

es difícil negar la absoluta insensatez de esta guerra. Si la guerra tenía como fin golpear a Bin Laden y a su red terrorista, entonces no solo se ha fracasado, sino que se han producido, como era del todo previsible, efectos exactamente 
opuestos: la popularidad de Bin La-den y de las sectas fundamentalistas crece entre las masas islámicas; la situación del medio oriente desde Pakistán a Israel es más explosiva que nunca; la inseguridad del mundo y los peligros de nuevas agresiones por parte de las organizaciones terroristas se hacen cada día más graves y alarmantes» (Ferrajoli, 2004).

Debido a lo que esté en juego, se debe de tener en cuenta criterios más drásticos. En relación a estas ideas, consideramos que un método para erradicar o disminuir la corrupción de las instituciones encargadas de la investigación en el delito de lavado de activos sería el establecimiento de órganos de control que se encuentren dispersos para de esa forma evitar acciones colusorias entre los delincuentes y los que investigan. Esta propuesta tiene criterios lógicos, la acción de dividir un ente fiscalizador propicia la difuminación de actos de corrupción y, por ende, se genera que se maximice la eficacia en cuanto a la persecución penal.

\section{SOBRE EL DELITO DE LAVADO DE ACTIVOS}

El delito de lavado de activos es un fenómeno delictivo complejo. La criminología lo define como un proceso en el cual los ingresos obtenidos a través de un acto ilícito (denominado delito fuente) son dotados de apariencia de legalidad mediante la realización de actividades económicascomerciales para posteriormente ser ingresados o insertados en el circuito económico legal (Mendoza, 2017, p. 80).

La tipificación de este delito se ha constituido en una herramienta a través de la cual se lucha continuamente contra la criminalidad organizada, pues se espera su disminución. La tipificación de un delito se justifica en la protección de determinados bienes jurídicos. Respecto al delito en estudio existen varias posiciones que indican los distintos bienes jurídicos que protege el lavado de activos. La primera es planteada como un delito uniofensivo. Esta parte de la doctrina ha indicado que el bien protegido es la administración pública, ya que afecta directamente la labor de las autoridades de persecución y represión penal (Hurtado, 2011, p.12).

Asimismo, han indicado que el bien jurídico es el mismo que protege el delito previo, dado que con el lavado de activos se mantiene o incrementa la lesión o puesta en peligro del bien jurídico que se vio afectado por el delito previo (Palma, 2000, p. 239). Para otro sector de la doctrina, 
se protege la seguridad interior del Estado, debido a que se combate la delincuencia organizada, la acción está dirigida a impedir o reducir la capacidad operativa para su filtración en el Estado (Aránguez, 2000, p. 271), en el orden socioeconómico, pues este es un objetivo político criminal empleado como criterio de sistematización para agrupar diversas figuras delictivas (Martínez, 2015, p. 78).

La segunda posición lo plantea como un delito pluriofensivo, es decir, que lesiona los bienes jurídicos indicados en el párrafo anterior, pudiendo ser todos ellos o dos de estos, cuando menos. Bajo estas premisas, consideramos que el bloque protegido es el orden socioeconómico; coincidimos con el planteamiento señalado por Fidel Mendoza, quien señala que la libre y leal competencia constituye el bien jurídico colectivo protegido en la incriminación del lavado, lo que justifica el empleo de la estructura del peligro abstracto como técnica de tipificación (Mendoza, 2017, p. 207).

Como se advirtió líneas arriba, el lavado de activos es un delito de peligro abstracto porque analiza la peligrosidad de la conducta que singulariza al delito, el comportamiento incriminado, superando el riesgo permitido, está dirigido a «evitar la identificación» del origen ilícito de los activos, su incautación o decomiso, "para ocultar o encubrir», "para ayudar» a tales fines.

El lavado de activos constituye un proceso secuencial mediante el cual los bienes de fuente criminal, a través de distintas operaciones, se reintegran al tráfico económico legal con «apariencia» de haber sido obtenidos de manera lícita, lo que implica un acto de 1) conversión o transferencia (disposición física del dinero), de 2) transporte (separación de fondos ilícitos) y de 3) tenencia (apariencia legítima).

\section{ANÁLISIS ESTADÍSTICO SOBRE EL INCREMENTO O DIS- MINUCIÓN DE LA CONCURRENCIA DEL DELITO}

Adicionalmente a lo señalado en el punto II del presente trabajo, los resultados del reporte estadístico de los Reportes de Operaciones Sospechosas (ROS), remitidos por Cooperativas de Ahorro y Crédito, elaborado por la Superintendencia de Banca, Seguros y AFP, muestran que la profesión u ocupación más reportada con movimiento sospecho en su estado financiero y con gran tendencia a que su posible actividad conlleve 
una investigación por el delito de lavado de activos es la de comerciante (16 $\%$ ), seguida de agricultor (13\%) y contador (5\%) (Superintendencia de Banca, Seguros y AFP, 2016, p. 19). A partir de estos resultados, podemos concluir que, al margen de reducir los niveles delictivos respecto a este ilícito penal, la cifra va aumentando con el transcurso del tiempo, si bien no es posible reducir del todo el grado de incidencia de este delito, es pertinente conocer cuáles son las principales herramientas para una mayor persecución y procesamiento de casos de lavado de activos, ello a fin de conseguir datos estadísticos alentadores, como resultado de una mejor gestión en la persecución y sanción de estos delitos.

\section{ANÁLISIS CRÍTICO DE LA VINCULACIÓN ENTRE FUN- CIONARIOS O SERVIDORES PÚBLICOS DENTRO DE OR- GANIZACIONES CRIMINALES DEDICADAS A LA COMI- SIÓN DEL DELITO DE LAVADO DE ACTIVOS}

Hoy en día el Perú es considerado como uno de los países con mayor dinamismo económico en Latinoamérica, siendo miembro fundador de la Alianza regional del Pacífico, así como integrante de la Cooperación Económica Asia-Pacífico (APEC) y la Comunidad Andina. Del mismo modo, tiene numerosos acuerdos de libre comercio con países del primer mundo, tales como Estados Unidos, la Unión Europea e incluso China. Sin embargo, a pesar del continuo desarrollo del país, la escena política se ha visto sacudida por una serie de escándalos de corrupción e investigaciones contra funcionarios y servidores públicos (como expresidentes), entre otras figuras políticas reconocidas.

La mayor de estas investigaciones es el escándalo transnacional de la constructora Odebrecht, que se centra en mecanismos de soborno utilizados por el grupo de construcción brasileño. Durante los años recientes, este ilícito se ha incrementado en sus distintas modalidades, los cuales han sido cometidos tanto por personas naturales como jurídicas. La sociedad ha sido testigo de los casos en los que están comprendidos los expresidentes: Alejandro Toledo Manrique, Ollanta Humala Taso y el desaparecido Alan García Pérez, todos ellos investigados o procesados por el presunto delito de lavado de activos, dinero proveniente de la corrupción de funcionarios, como es el caso de la empresa constructora brasileńa Odebrecht, que habría sobornado a altos funcionarios de 28 países, entre otros el Perú. Los 
funcionarios del Perú se habrían recibido dinero ilícito, el cual habría sido ocultado mediante transferencias y conversiones de diferentes bienes, tales como la adquisición de muebles e inmuebles, constitución de empresas, inversiones en la bolsa de valores, e incluso el uso de testaferros, entre otros; todo ello, con el fin de evitar su identificación e incautación de estos activos de origen ilegal.

Debido a la naturaleza de estas investigaciones, el Ministerio Público viene conociendo varias denuncias por delitos contra la administración pública, a un nivel sin precedentes. Casos de cohecho y malversación de fondos se van relacionando con el delito de lavado de activos, que hace mucho más compleja la investigación que Ministerio Público está realizando actualmente. De ello se ha hecho evidente que la corrupción ha repercutido en la mayoría de sectores políticos y relacionados con la Administración Pública, al menos desde el auge del desarrollo de infraestructura que comenzó a principios del ańo 2000, el Perú se convirtió en un destino atractivo para las inversiones y los negocios en América del Sur debido a su economía variante pero controlada. Esta calma económica llevó a importantes proyectos de infraestructura financiados por el Gobierno que se prestaron fácilmente a actividades financieras ilegales.

Pero ¡cuán relevante es la participación de los funcionarios y servidores públicos en las organizaciones criminales? Según la teoría del maestro Claus Roxin, el grado de participación de estos se encuentra sustentada en el deber especial que infringe el sujeto, el cual llevaría a sustentar la imputación en su contra, ya que como señala «la autoría le corresponde a aquella persona que estando obligado institucionalmente a cumplir con un deber positivo especifico lo incumple.» (Roxin, 1998, p. 386). En ese sentido, según el informe estadístico del Ministerio Publico, durante el año 2017 se registraron más de 509 denuncias ante la Fiscalía Especializada en delitos de Corrupción de Funcionarios del distrito Fiscal de Lima, de los cuales 26 conllevaron una investigación por el delitos de Lavado de activos, siendo 17 las que se encontraban aun en trámite pendiente de calificación y posible disposición de archivo (Ministerio Público, 2017, p. 53), que en comparación con el número de casos presentados en sede fiscal el año 2013, este se ha visto incrementado de manera considerable (Ministerio Público, 2013, p. 64).

Estos hechos se han visto expuestos por labor de los medios de comunicación, que han dano a conocer cómo funcionaban algunas de las más grandes 
organizaciones criminales en nuestro país, evidenciando, lamentable, la presencia de algunos funcionarios públicos de alto renombre, como en los casos de la «La Centralita» y de «Rodolfo Orellana»; a medida que se avanzaban las investigaciones se veían involucrados personajes que la sociedad creía que cumplían cabalmente con sus funciones. En ese contexto se entiende que la conducta punible se da en mérito al quebrantamiento de deberes especiales, relacionados con la salvaguarda del bien jurídico tutelado.

Las investigaciones a las que se hace referencia líneas arriba dejaron en manifiesto cómo altos funcionarios se encontraban inmiscuidos en diversas organizaciones criminales con las cuales evitaban que los servidores públicos o inclusive los mismos funcionarios, con los que guardan cierta relación de afinidad, no llevaran correctamente las investigaciones por varios actos delictivos, dejando un mensaje negativo a la población, en vista de que al ver que estaban involucrados policías, jueces y fiscales, se ponía en discusión las bases democráticas que deben caracterizar a toda sociedad, por lo que la participación de funcionarios públicos en organizaciones criminales no sólo constituye un delito, sino que genera desconfianza, ya que existe el temor de que este actué también para su propio beneficio. Esta afirmación tiene sustento en los resultados de la X Encuesta Nacional sobre percepciones de la corrupción en el Perú, realizada en el año 2017: el 52 \% del total de encuestados afirma que la corrupción de funcionarios y autoridades es el principal problema del Estado peruano (Proética, 2017, p. 19).

Ante un problema como este de naturaleza pandémica, se busca luchar mediante tratados internacionales, como la Convención Interamericana contra la Corrupción o la Convención de las Naciones Unidas contra la Corrupción, con ello se espera iniciar un proceso de transformación de conductas éticas con el transcurrir del tiempo.

\section{MICHEL FOUCAULT: «UNA VISIÓN PROFUNDA DEL ÁMBITO PENAL APLICADO CRÍTICAMENTE AL DELITO DE LAVADO DE ACTIVOS»}

El filósofo francés Michel Foucault, en un escrito nos plantea más que respuestas preguntas, que analizadas cuidadosamente nos ayudan a visualizar la problemática social que se vive mediante el aparato punitivo 
estatal. ¿Qué tan cierto es que los delincuentes que se encuentran dentro de las cárceles son los «tontos», los "primerizos», «incompetentes»? ¿Por qué los delincuentes capos no están encerrados? ¿Por qué siempre el aparato estatal, mediante sus órganos públicos encargados, miran la cola de la criminalidad organizada y no al agente que es la "cabeza»? ¿Se constituye una cortina de humo la incautación de algunas toneladas de dinero ilícito o droga, mientras por otro extremo se exporta el quíntuple de dinero o bienes ilícitos? Estas son algunas de las preguntas que mantienen latentes nuestra capacidad investigativa, y más aun analizando la obra mencionada.

El libro de Foucault se desarrolla en cuatro capítulos bien puntualizados, el primer capítulo, titulado Suplicio, es el que (palabras más, palabras menos) detalla el porqué del castigo, además de su origen y naturaleza, al ser tomado como un aleccionamiento al haber atentado contra el monarca o rey según el contexto cultural y social, mostrando una constante manifestación del poder, entre el que castiga y el que es castigado (Foucault, 1993).

Dentro de este esquema el delito de lavado de activos atenta contra la soberanía del Estado, por lo que vale la pena hacer la siguiente pregunta: ¿quién es realmente o qué es realmente un soberano? ¿Se protege el status quo de los poderosos y no el de la población?

En el segundo capítulo, titulado Castigo, el autor refiere que hemos pasado del castigo corporal a un castigo de restricción de un derecho o bien, concibiendo así a la sanción punitiva como una economía de derechos suspendidos. Denotando una férrea intolerancia a los delitos económicos, siendo que el castigo se concibe como una técnica de coerción, mediante el cual el poder mantiene su hegemonía, valga hacer la pregunta crítica ¿Quiénes tienen el poder?, ¿la población?. Los crímenes de cuello blanco desatan el furor ante un sistema de producción liberal, al perjudicarse el esquema financiero instaurado.

El tercer capítulo, cuyo título es Disciplina, explica porqué la institución carcelaria deviene en la forma privilegiada de castigo, pues arquitectónicamente la prisión permite una vigilancia invisible, implica la existencia de funcionarios que están continuamente examinando y, por tanto, realizando una función de jueces, obliga al trabajo rítmico en forma de ejercicio. Tratándose así de purificar el alma del delincuente «tonto» para que al menos brinde a la sociedad un mínimo valor utilitario y a la vez sirva como 
un chivo expiatorio que pague las acciones de las mafias específicamente de los delincuentes de «verdad».

El tercer capítulo de la obra está muy correlacionado con el último que lleva como sumilla Prisión, concibiéndose en ya no como un medio de purificación del hombre (dándole un valor agregado al utilitarismo económico) sino como una cortina de humo, que hace que la población se mantenga ecuánime, bajo la premisa «nuestras autoridades están luchando contra la delincuencia». Mientras en el trasfondo simplemente es una forma de inocuizar el pensamiento crítico por el temor, ya que las clases marginales son las que en su mayoría sufren el látigo del poder punitivo del Estado, mas no las clases pudientes. Un pueblo sustentado en la ignorancia está condenado a vivir de lo que le digan, mas no de lo que es.

\section{EL PODER PUNITIVO EN LOS ESTADOS ACTUALES, UN CRITERIO ANALÍTICO EN CORRELACIÓN CON EL DELITO DE LAVADO DE ACTIVOS}

Aquella denominación del Estado como un leviatán, concebida como la fuerza más aterradora que el ser humano podría soportar, al parecer entendida en el contexto contemporáneo, poco a poco está perdiendo impacto social. Una de las razones es la pérdida de eficacia, en cuanto a la persecución penal, la falta de preparación de los sujetos pertenecientes a los entes estatales (como el Ministerio Público), entre otras razones. Estas circunstancias contextuales en el ámbito peruano ocasionan que se debiliten los ejes rectores para la búsqueda de un Estado propiciador del bien común, fallando en sus aspiraciones a favor de un bien común para pocos a costa del dolor de muchos.

\subsection{La perversión del sistema económico}

Las actividades destinadas a limpiar el dinero de las máculas con las cuales se obtuvieron generan que, aparentemente, un Estado se desarrolle económicamente, siendo esto falaz, pues el dinero obtenido no tiene un control fiscal y, por tanto, el Estado no puede percibir los tributos que permitirán la inversión pública. Además, el lavado de activos incentiva la ilegalidad (en el mejor de los casos la informalidad), la explotación y el irrespeto de los derechos fundamentales de manera importante. 


\subsection{La pluralidad de daños conexos al delito de lavado de activos}

Una visión simplista del delito de lavado de activos llevaría a plantear que su único daño es el correcto orden económico, lo cual, desde nuestra perspectiva, es cierto. Sin embargo, bajo un criterio holístico, con este delito conexamente se daña también la soberanía del Estado, la democracia, la estabilidad, el bien común, la sostenibilidad, fines que son truncados en cuanto a su realización debido a las repercusiones indirectas de este delito. Por ejemplo, el lavado de activos si bien tiene un criterio autónomo bajo su regulación en nuestro Código Penal peruano, se debe - bajo una interpretación sistemática - indagar los pasos que se siguen para su culminación, más aún si la investigación fiscal tendría que necesariamente tocarse con la realización de otros delitos.

\section{FACULTADES DE LA UNIDAD DE INTELIGENCIA FI- NANCIERA EVALUADAS EN FORMA CRÍTICA}

La Unidad de Inteligencia Financiera (UIF) se consagra como la institución especializada en la lucha contra el delito de lavado de activos en nuestro país o financiamiento del terrorismo (en adelante, LAFT). Fue creada mediante Ley N. 27693 de abril del 2002, modificada por las leyes N. ${ }^{\circ}$ 28009 y N. ${ }^{\circ} 28306$ y reglamentada mediante el Decreto Supremo N. ${ }^{\circ} 163$ -

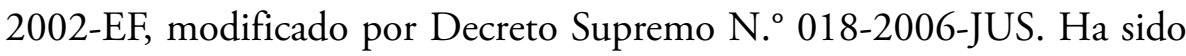
incorporada como Unidad Especializada a la Superintendencia de Banca, Seguros y Administradoras Privadas de Fondos de Pensiones mediante Ley N. 29038 de junio del año 2007, y tiene autonomía funcional y técnica.

Mediante la intervención de la Unidad de Inteligencia Financiera (UIF), se propicia la evaluación minuciosa de las transacciones de dinero en el Perú; asimismo, se encarga de emitir un informe en el que detalla algunas operaciones sospechosas, función que realiza mediante un trabajo dividido y organizado de la siguiente forma: primero, el Departamento de Análisis Operativo tiene a su cargo el tratamiento, evaluación y análisis de la información recibida que permita identificar casos en los que se presuma la existencia de operaciones de LAFT; segundo, el Departamento de Análisis Estratégico y Desarrollo elabora estudios de inteligencia estratégica, estudios socioeconómicos y sectoriales, informes especializados y tipologías 
de LAFT; tercero, el Departamento de Prevención, Enlace y Cooperación tiene a su cargo la elaboración de proyectos de normas internas en materia de LAFT, de proponer políticas y estrategias nacionales, así como normas y procedimientos para la prevención de LAFT por parte de los Sujetos Obligados, bajo un enfoque de riesgo, de emitir Directivas UIF, modelos de Códigos de Conducta, Manual de Prevención y otras herramientas relacionadas con el Sistema de Prevención de LAFT; cuarto, el Departamento de Supervisión tiene a su cargo la supervisión de la implementación del Sistema de Prevención de LAFT a los sujetos obligados bajo la competencia de la SBS, a través de la UIF-Perú, según un enfoque basado en riesgos, de acuerdo con sus propios mecanismos de supervisión, los cuales deben considerar las responsabilidades y alcances de los informes de los Oficiales de Cumplimiento, de la Auditoría Interna y de la Auditoría Externa, cuando corresponda, así como las responsabilidades de los directores y gerentes, quinto el Departamento de Evaluación y Acciones Correctivas tiene a su cargo la difusión y capacitación sobre principios, normas, políticas, tipologías y otra información relevante en materia de LAFT y, finalmente, el Departamento de Coordinación Técnica y Desarrollo es el encargado de apoyar a la Superintendencia Adjunta en su gestión técnica y operativa para el cumplimiento de sus funciones, informando sobre la evolución y tendencias internacionales respecto del desarrollo de los Sistemas antilavado de Activos y Contra el Financiamiento del Terrorismo.

¿Cómo se vinculan los esfuerzos por combatir el LA y el FT? A diferencia del caso de LA, los recursos utilizados para apoyar el terrorismo pueden provenir tanto de fuentes legítimas como de actividades ilícitas. No obstante, encubrir el origen de los fondos destinados a FT se mantiene como una actividad esencial para el delincuente, independientemente de si la fuente es de origen legítimo o ilícito. Las técnicas utilizadas para el LA son esencialmente las mismas que aquellas utilizadas para ocultar las fuentes y la utilización de fondos para la financiación del terrorismo. Un marco efectivo para la lucha ALA y de combate al financiamiento del terrorismo (CFT) debe, por lo tanto ,abordar ambos problemas.

Asimismo, las estrategias ALA y CFT convergen. Ambas apuntan a atacar a los criminales o terroristas a través de sus actividades económico-financieras, y utilizar el rastro económico-financiero para identificar los varios componentes de las redes criminales o terroristas. Esto implica poner en su lugar mecanismos tendientes a prevenir el abuso de los sistemas económi- 
cos y financieros y a detectar operaciones sospechosas. ¿Por qué hace falta un Plan Nacional para luchar contra el LA/FT? Las organizaciones criminales y terroristas operan de manera altamente organizada con sus propios planes de enriquecimiento y expansión.

Por lo tanto, es imprescindible hacer frente a dicha amenaza de manera igualmente organizada y mediante un plan que ordene las acciones estatales hacia la finalidad deseada. Por otro lado, es imprescindible contar con un Plan Nacional como herramienta para ordenar el amplio esfuerzo de coordinación a nivel inter institucional entre diversas autoridades de supervisión, de inteligencia, policiales, fiscales, y judiciales que la implementación de medidas ALA/CFT demanda.

Como ya ha sido señalado, se advierte la carencia de preparación de los funcionarios y servidores públicos que se dedican a la lucha contra la actividad de crimen organizado, lleva consigo un desmérito, pues la actividad criminal ha establecido una gran distancia de la actividad fiscal. ¿Será que existen indicios de corrupción en nuestras instituciones estatales que tienen por función combatir el lavado de activos? La situación es alarmante, debido a que no solo se deja al libre arbitrio de los delincuentes la comisión de ilícitos, sino indirectamente se les deja la facultad de determinar el avance o deterioro económico de un país, propiciando así cada vez más la creación de paraísos económicos.

\section{PROPUESTA O POSIBLE MAXIMIZACIÓN DE LA EFICACIA CONTRA LA LUCHA DEL DELITO EN ANÁLISIS}

Es un acierto del legislador haber dotado de autonomía típica cada etapa de este proceso y en consecuencia hacer que se persiga penalmente a quien participe de este delito, ya sea en actos de conversión o tenencia, así como de ocultamiento y la tenencia de activos de origen ilícito, debido a que devendría en un hecho imposible investigar y probar que un solo sujeto participó y realizó todo este proceso al que denominamos lavados de activos. Sin embargo, podemos advertir que, según la Procuraduría Pública de Lavado de Activos, del 2016 junio de 2018, se registraron 2763 investigaciones y procesos en trámite. A pesar de ello, la Sala Penal Nacional señala que en un periodo similar hubo solo 41 sentencias, de las cuales 31 fueron absolutorias (Pachuri, 2019). 
A partir de estas cifras, se concluye que una forma eficaz de luchar contra el delito de lavado de activos es la lucha contra los denominados delitos fuentes de donde se percibe el dinero que se pretende lavar, como el delito de minería ilegal, debido a que las sentencias condenatorias obtenidas desalientan a aquellos que tienen como función y deber perseguir este delito. También es motivo de alarma debido a que solo se obtuvieron 10 sentencias condenatorias de todos los procesos que llegaron a juicio oral, lo cual significa que las organizaciones criminales logran ingresar al sistema socioeconómico camuflando el ilícito origen de los activos mal habidos.

Ante este problema nace la siguiente cuestión: ¿es eficaz la lucha contra el delito de lavado de activos? Creemos que no por lo señalado en las páginas anteriores. Asimismo, es necesario recalcar que organismos internacionales han brindado pautas y consejos para obtener una lucha más eficaz contra el delito de lavado de activos. Organizaciones como las Naciones Unidas, el Consejo de Europa y el Grupo de Acción Financiera Internacional (GAFI) se pronunciaron ante la difícil tarea de investigar y sancionar a quienes incurren en delito de blanqueo de bienes, así como los problemas de tipicidad y la regulación de este delito. Ante nuestra consideración aquello que importa mayor dificultad es la etapa de investigación del delito para reunir los suficientes elementos de convicción y llegar a juicio oral, por esta razón consideramos las siguientes pautas:

- En primer lugar, consideramos necesario que todas aquellas personas que fueron condenadas, así como aquellas que son investigadas por delitos cometidos mediante organización criminal sean investigados por lavado de activos, pues resulta razonable y necesario que las personas que participan de organizaciones criminales tienen por objeto sacar provecho económico de sus actividades ilícitas. Esto nos lleva a la gran probabilidad de que actúen para dotar al dinero de origen ilícito con una apariencia de legalidad.

- Mencionado lo anterior, se advierte la carga procesal que se generaría al investigar a las personas que cometieron delitos mediante una organización criminal, por esta razón es necesario hacer un filtro en función a las actividades criminales que se realizaban dentro de la organización debido a que son estas las que nos indican el fin lucrativo del delito fuente. Otro grupo de sujetos, cuya investigación debe ser obligatoria, son aquellos que son condenados y aquellos que son investigados por 
delitos de corrupción y cuyos montos dinerarios obtenidos ilícitamente se estimen elevados a raíz de la investigación del posible delito fuente.

- Otra manera de buscar una lucha más eficaz contra este ilícito penal sería la implementación de políticas y leyes antilavado para los bancos, dándoles la categoría de tercero civilmente responsable a las entidades financieras y bancos que no presten atención y no apliquen eficazmente u oportunamente el sistema antilavado, así de esta manera estas organizaciones tendrán un motivo más para estar alertas en esta ardua lucha.

- Continuando con las pautas para coadyuvar la lucha contra el lavado de activos, es urgente desactivar el desfasado Plan Nacional contra el Lavado de Activos y el Financiamiento del Terrorismo 2018-2021 para implementar un nuevo plan de acuerdo con las exigencias de la realidad social de nuestro Estado, apelando a leyes que hagan posible una mayor colaboración interinstitucional de nuestros órganos estatales poniendo bajo responsabilidad a los funcionarios por la falta de acción frente al pedido de información o apoyo en la investigación de este delito, esto debido a la corrupción enquistada en toda rama y nivel de los órganos estatales que muchas veces traban o estorban a propósito la instrucción de este delito debido a que se encuentran vinculados en este ilícito proceder.

La lucha contra este delito no sólo presenta dificultad en su investigación, sino también una gran problemática al momento de mencionar la colaboración de las instituciones estatales que muchas veces están interesadas en que las investigaciones no lleguen a buen puerto. La colaboración interinstitucional no debe restringirse a una cooperación entre organismos estatales o públicos. GAFI, entre las pautas u consejos brindados exhorta a las instituciones financieras a constituir e integrar un Comité de Comunicación y Control cuya función sea la de inspeccionar la correcta implementación de las políticas antilavado.

La colaboración interinstitucional es un factor clave para fortalecer la lucha contra el delito de blanqueo de bienes, necesario en tanto que la prueba indiciara cumple un rol importante al momento que resulte indispensable probar ante el juez la responsabilidad de los sujetos en juicio oral, es con esta cooperación entre las instituciones financieras mediante las cuales se pueden llegar a obtener los indicios necesarios para descubrir el origen ilícito de los activos e impedir que dinero obtenido producto de activida- 
des ilícitas ingresen al sistema económico legal y, en consecuencia, que las organizaciones criminales se infiltren en la sociedad.

Ante la variedad de factores por investigar para lograr una mayor eficacia en la erradicación de este delito es notorio que no será suficiente este espacio para culminar con esta labor académica y ante el mencionado escenario debemos limitar por esta oportunidad la extensión del presente segmento.

\section{CONCLUSIONES}

- Es preocupante que la autonomía de los entes encargados de la persecución del delito de lavado de activos sea en estos últimos tiempos muy cuestionada. Entonces, si estos entes, en la «mayoría de casos», delegan sus facultades a los delincuentes, simplemente la sociedad pierde su objeto.

- El delito de lavado de activos es un fenómeno delictivo complejo. La criminología lo define como un proceso en el cual los ingresos obtenidos (dinero) a través de un acto ilícito (denominado delito fuente) son dotados de apariencia de legalidad mediante la realización de actividades económicas-comerciales para posteriormente ser ingresados o insertados en el circuito económico legal.

- A pesar del continuo desarrollo del país, la escena política se ha visto sacudida por una serie de escándalos de corrupción e investigaciones contra funcionarios y servidores públicos, como expresidentes, entre otras figuras políticas reconocidas.

- Prisión, el término se concibe ya no como un medio de purificación del hombre, dándole un valor agregado al utilitarismo económico, sino como una cortina de humo para que la población se mantenga ecuánime, bajo la premisa «nuestras autoridades están luchando contra la delincuencia», mientras en el trasfondo, simplemente, es una forma de inocuizar el pensamiento crítico por el temor, ya que las clases marginales son las que sufren el látigo del poder punitivo del Estado, mas no las clases pudientes. Un pueblo sustentado en la ignorancia está condenado a vivir de lo que le digan, mas no de lo que es.

- Una visión simplista del delito de lavado de activos llevaría a plantear que su único daño es el correcto orden económico, lo que para nosotros es acertado. Sin embargo, bajo un criterio holístico, con este delito conexa- 
mente se daña también la soberanía del Estado, la democracia, la estabilidad, el bien común, la sostenibilidad, fines que son truncados en cuanto a su realización debido a las repercusiones indirectas de este delito.

- ¿Es eficaz la lucha contra el delito de lavado de activos? Creemos que no. En primer lugar, consideramos necesario que todas aquellas personas que fueron condenadas, así como aquellos que son investigadas por delitos cometidos realizados mediante organización criminal, sean - a su vez - investigados por lavado de activos porque resulta razonable y necesario que las personas que participan de organizaciones criminales tienen por objetivo sacar provecho económico de sus actividades ilícitas, lo cual lleva a gran probabilidad de que actúen para dotar al dinero de origen ilícito con apariencia de legalidad, de tal manera que queda abierta la posibilidad de investigar a un mencionado grupo de personas.

- Otra manera de buscar una lucha más eficaz contra este ilícito penal podría ser la implementación de políticas y leyes antilavado aplicada a los bancos, dándoles la calidad de tercero civilmente responsable a las entidades financieras que no presten atención y no apliquen eficazmente u oportunamente el sistema antilavado. De esta manera, estas organizaciones tendrán un motivo más para estar alertas en esta ardua lucha.

- Es urgente desactivar el desfasado Plan Nacional contra el Lavado de Activos y el Financiamiento del Terrorismo 2018-2021 para implementar un nuevo plan de acuerdo a las exigencias de la realidad social de nuestro Estado, apelando a leyes que hagan posible una mayor colaboración interinstitucional de nuestros órganos estatales poniendo bajo responsabilidad a los funcionarios por la falta de acción frente al pedido de información o apoyo en la investigación de este delito.

\section{BIBLIOGRAFÍA}

Aranguéz, C. (2000). El delito de blanqueo de capitales. Madrid: Marcial Pons.

Ferrajoli, L. (2004). Las razones del pacifismo. Jueces para la Democracia, 50.

Foucault, M. (1993). Vigilar y castigar: Nacimiento de la prisión. 2. ${ }^{a}$ ed. Trad. Aurelio Garzón del Camino. México D.F.: Siglo XXI.

Hurtado, J. (2011). Droit penal économique: questions de a partie générale. Zurich: Schukthess Juristische Medien AG. 
Martínez, C. (2015). Derecho penal económico y de la empresa. Valencia: Tirant lo Blanch.

Mendoza, F. (2017). El delito de lavado de activos. Lima: Instituto Pacífico.

Ministerio Público. (2017). Anuario estadístico. Lima: Orace.

Ministerio Público. (2013). Anuario estadístico. Lima: Orace.

Pachuri, F. (2019). Lucha contra la Corrupción del IDEHPUCP. Recuperado de https://puntoedu.pucp.edu.pe/opinion/peru-el-silencio-ante-el-lavado-de-activos/.

Palma, H. (2000). Los delitos de blanqueo de capitales. Madrid: Edersa.

Proética (2017). Percepción de corrupción. Lima: Capitorio Peruano de Transparency International.

Roxin, C. (1998). Autoria y dominio del hecho en el derecho penal. Madrid: Marcial Pons.

Superintendencia de Banca, Seguros y AFP (2016). Reporte estadístico de los reportes de operaciones sospechosas remitidos por cooperativas de ahorro y crédito. Lima. 